\title{
Designing Smart Home Using Cisco Packet Tracer
}

\author{
Sibbala Manoj Kumar ${ }^{a}$, Gandikota Harsha Wardhan ${ }^{b}$, Shubham Khandelwal ${ }^{c}$, Aditya Singh ${ }^{d}$, Rohith \\ Moola ${ }^{e}$ Yedamakanti Srinivas Reddy ${ }^{f}$, Dr. V. Megala ${ }^{g}$ \\ ${ }^{\mathrm{a}-\mathrm{g}} \mathrm{SRM}$ Institute of Science and Technology, Ramapuram Campus, Chennai \\ mk2638@srmist.edu.in ${ }^{\mathrm{a}}$,gw3819@srmist.edu.in ${ }^{\mathrm{b}}$,sk8182@srmist.edu.in ${ }^{\mathrm{c}}$, as6162@srmist.edu.in ${ }^{\mathrm{d}}$, \\ rm3352@srmist.edu.in ${ }^{\mathrm{e}}, \mathrm{yr} 4844 @$ srmist.edu.in ${ }^{\mathrm{f}}$, megala95@gmail.com $^{\mathrm{g}}$
}

\begin{abstract}
The world today has become the hub for new technologies and innovations leading to provide a better quality of life. It has become an essential requirement for everyone to stay updated with the current technologies. All the devices are turning out to be Smart Devices making a Smart Environment using various new technologies in which INTERNET OF THINGS (IOT) plays the major role.This paper explains designing of Smart Home which consists of IOT devices like fan, light, window, ac, heater, water sprinkler etc. using Cisco Packet Tracer Simulator. The main intention of this paper is to provide the Smart Home experience where all the Smart devices are controlled using a Smartphone which can be practically implemented in the real life.
\end{abstract}

Keywords: Cisco packet tracer, Gateway, IOT, Smart home, Smart phone

\section{Introduction}

Internet of Things can be defined as a network of devices connected with each other through the common gateway so called "Internet" to exchange data within the devices which are of wireless connections. IOT devices involve embedded systems, sensors, machine learning, automation, wireless sensor networks, control systems, softwares and other technologies[1].This concept of smart devices connected in a network was first in 1982, in which Coca-Cola vending machine became the first internet connected device which was able to detect whether it is cold or not. As per estimations by Cisco Systems, IOT was said to be born between 2008 and 2009. When it comes to Smart home, it must provide security in addition to the smart connectivity of devices. Security of the system plays a major role in avoiding data leaks or by systems getting hacked [2]. When it comes to implementation, Cisco Packet Tracer simulator is used for designing of this Smart Home. Cisco Packet Tracer is a Simulator which is powerful enough to build simple and complex networks easily. It also provides many inbuilt devices, components and all other things required for designing of networks. In this paper the latest version (8.0) of Cisco Packet Tracer is used to implement the designing of Smart Home and is shown in Figure 1 [3].

Cisco Packet Tracer fulfills the following requirements:-

- Provides user-friendly experience making it easy for beginners to learn the basics of the Simulator.

- Allows users to test their projects virtually before implementing them practically in order to verify the project with no cost.

- Provides real-time visualization of the processes that occur inside a system making it more realistic.

- Allows the users to test and improve their skills by providing interactive programmes. 
- It consists of all the required IOT components in order to build Smart cities, Smart Homes, Smart Villages, etc.

- It is a free simulation tool to download and is available to anyone.

- Allows the users to share the designed projects with Cisco for feedbacks.

- It also allows the user to run their projects in multiple devices by sharing the projects.

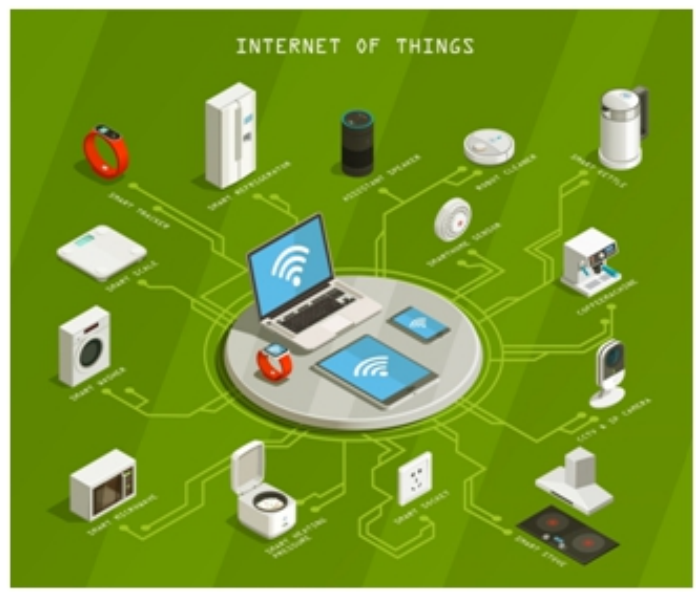

(a)

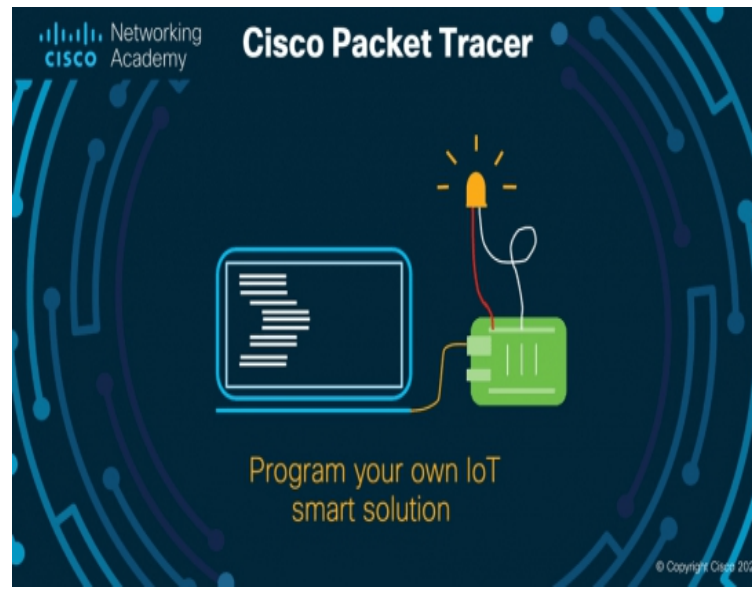

(b)

\subsection{Motivation}

Figure 1: a. Internet of Things, b. Cisco Packet Tracer Interface

As mentioned above Cisco Packet Tracer simulator provides all the facilities in order to design the Smart Home project [4]. The designing of this project is done using the latest Cisco Packet Tracer of the version 8.0 which consists the following new features when compared to previous old versions:-

- Newly designed user interface.

- A new Packet Tracer Network Controller in order to make easier centralized controlling of different networks and managing them.

- Provides a wide range of Wireless Coverage.

- Provides Access Point coverage Range which is not present in the previous version.

- A new Configuration Server is provided.

- Newly enhanced Physical Mode to provide better virtual experience.

- Online Web dashboard which is used to monitor, manage and configure devices across your network.

\subsection{Related work}

Smart Home is a place where the quality of living is improved and made the works simpler, where most of the devices have been connected to smartphone to control them using the common gateway. Various sensors have been chosen and implemented in this project in order to measure the required atmospheric conditions like temperature, humidity, water levels, motion of objects etc. 
International Journal of Intelligent Communication, Computing and Networks Open Access Journal (ISSN: 2582-7707)

https://doi.org/10.51735/ijiccn/001/26

The objects or devices that are automated in this project to design a Smart Home areFan, Lamp, Window, Door, Garage shutter, Lawn Sprinkler, Air Conditioner, Heater etc..,[4,5]

\section{Methodology}

The new Cisco Packet Tracer simulator is used to design Smart Home which consists of smart devices that are mentioned above. One can find these devices in bottom left corner after opening the Cisco Packet Tracer simulator as shown in the figure 2.

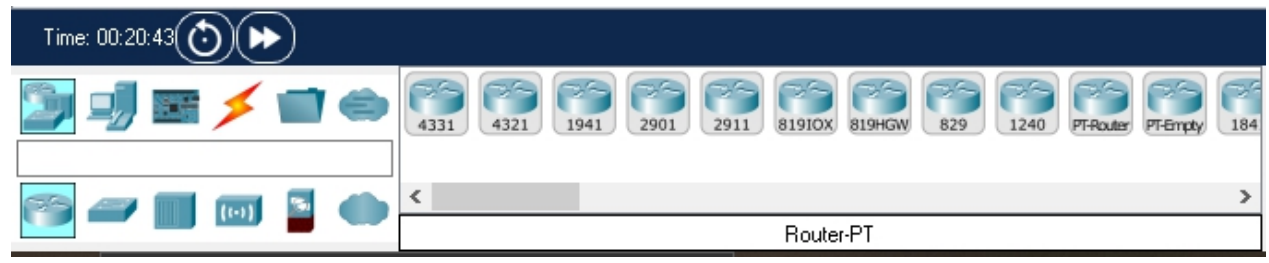

Figure 2: Available components in CISCO packet racer to design Smart Home

A Home Gateway is used to control the smart devices which are mentioned above. In the first step a home gateway is placed and its ipaddress is noted. Then a smartphone is selected and connected it to the Home gateway by entering the allotted name (HomeGateway) in SSID which is present in "Config" section followed by Wireless0 section as shown in figure 3. In order to open Config click on the smartphone icon and follow the steps mentioned above.

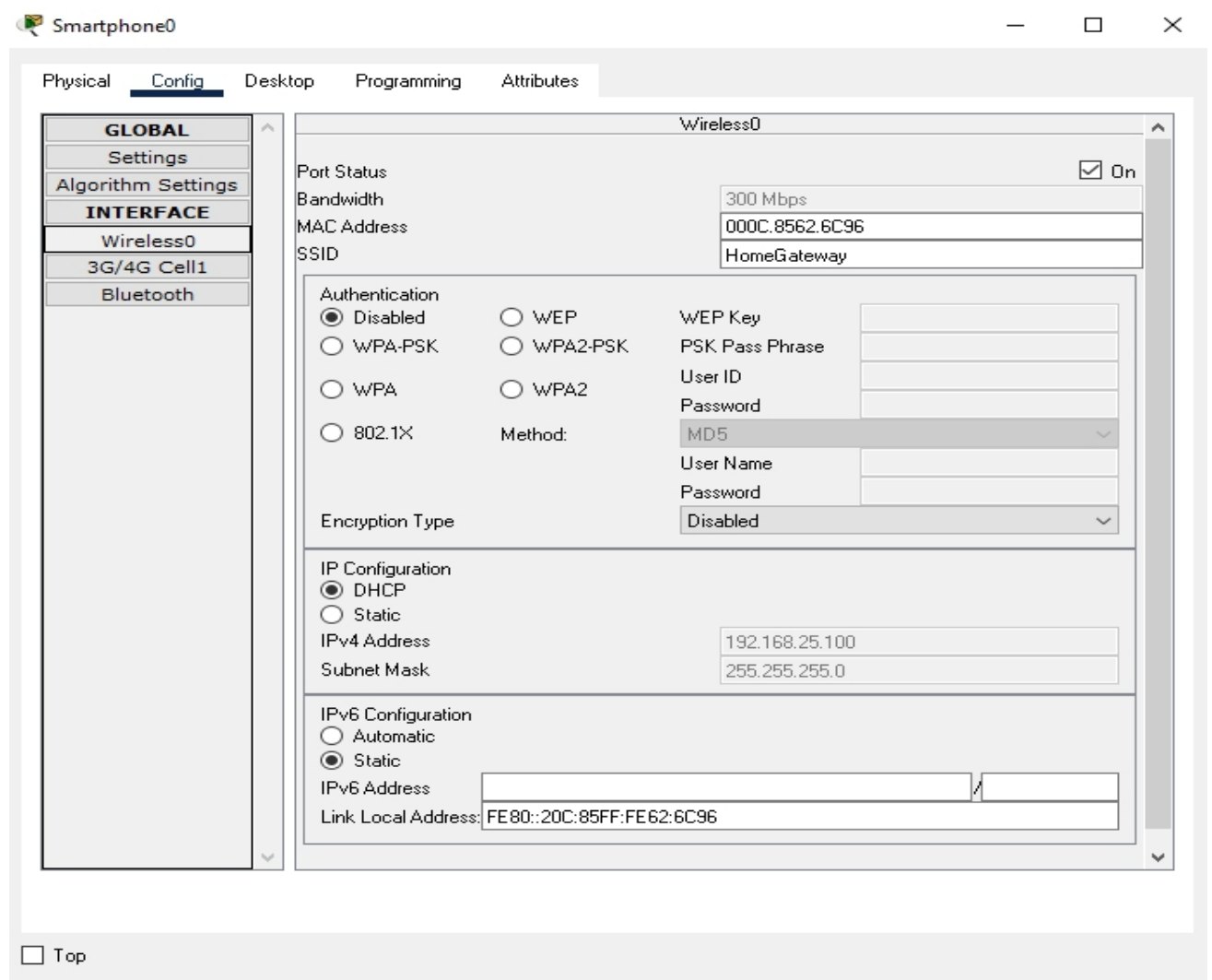

Figure 3:Snapshot of CISCO Packet racer describing Smartphone connected to Homegateway 
International Journal of Intelligent Communication, Computing and Networks Open Access Journal (ISSN: 2582-7707)

https://doi.org/10.51735/ijiccn/001/26

Home Gateway consists of 4 Ethernet ports along with wireless access point. The second step is after the smartphone being connected to HomeGateway, click on Desktop, enter the ip address of the HomeGateway, then enter Username (admin) and Password (admin), then submit, which then opens a window. Minimize the window and follow the further steps:-

- Select any smart device from the available components as shown in figure 2.

- $\quad$ Tap on the device and open config to select IOT server to Home Gateway.

- Then click advanced at the bottom right corner.

- Go to the IO Config and make the Network Adapterwireless (PT-IOT-NM-1W) which completely connects the device to home gateway wirelessly.

Follow the above given steps in order to add as many as required smart devices connecting them to the Home Gateway and smartphone. Now open the window which was minimized in step to view all the connected devices.

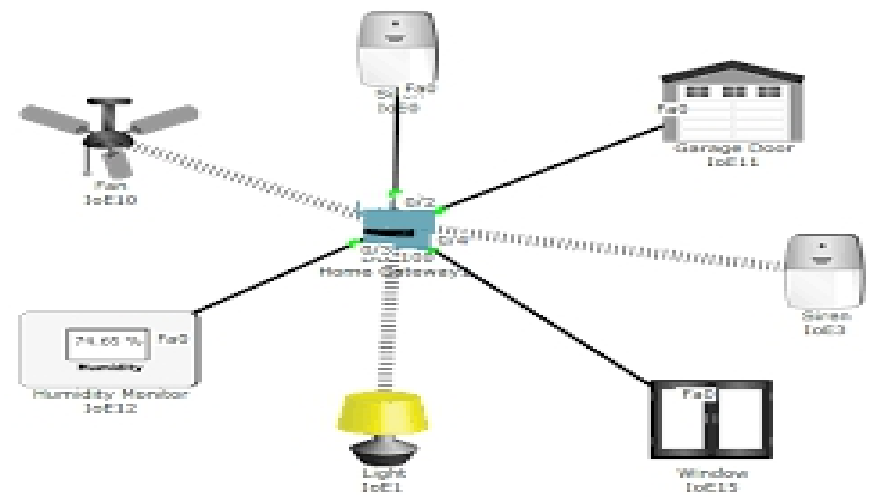

Figure 4: Connection of Home Gateway to smart devices

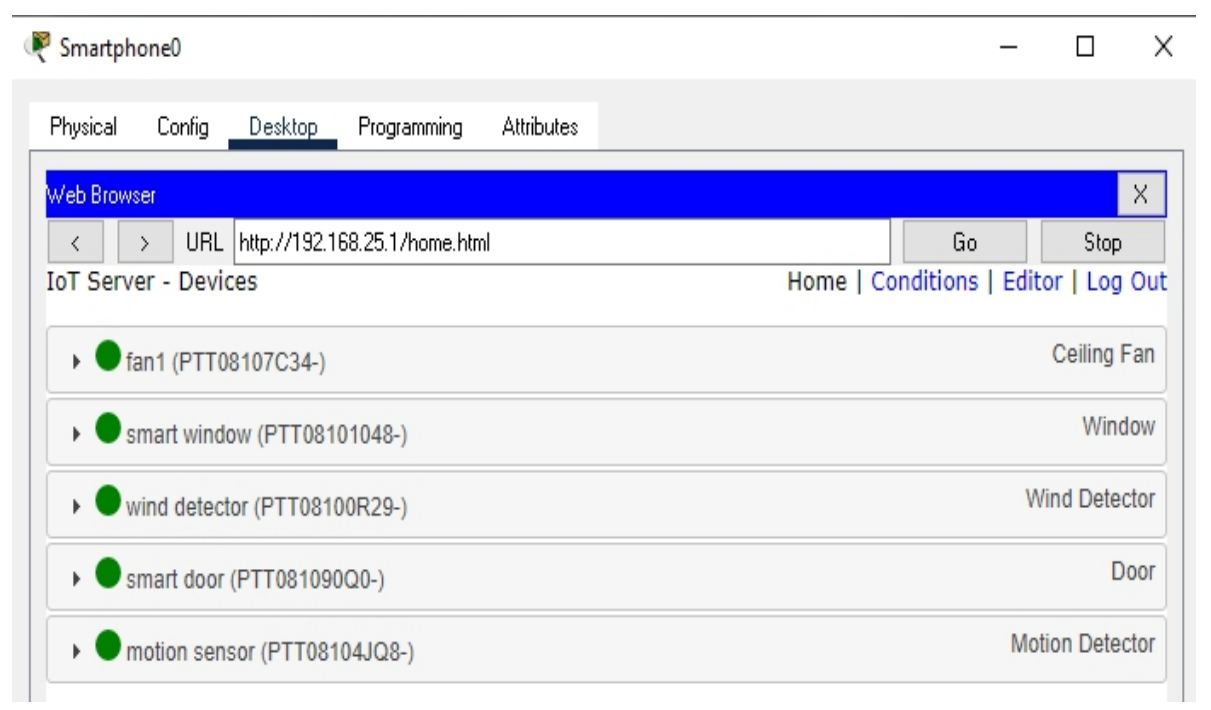

Figure 5: Information on Devices connected with smartphone

Figure 4 and 5 shows the successful connections of the smart devices with both home gateway and the 
International Journal of Intelligent Communication, Computing and Networks Open Access Journal (ISSN: 2582-7707)

smartphone.

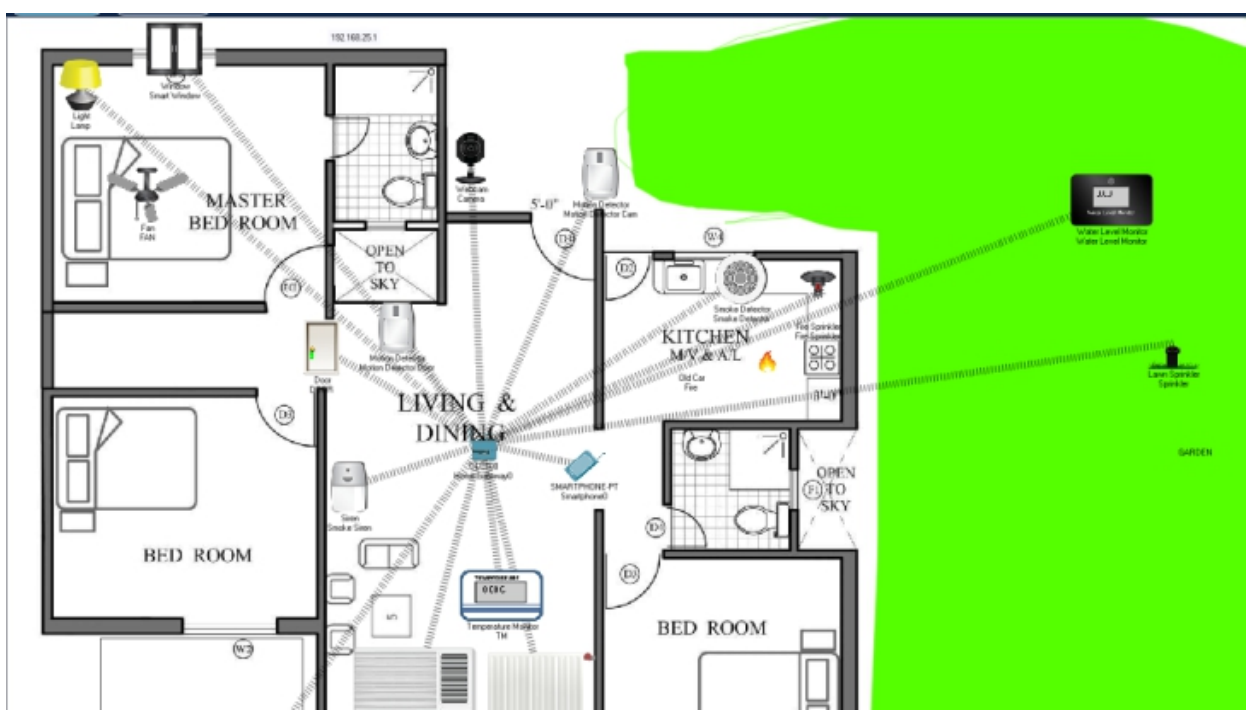

Figure 6: Smartdevices and sensors connected to home gateway using CISCO packet racer

As shown in the figure 6 this project of designing SmartHome consists of the following layout where the background layout can be downloaded from the internet and placed in cisco packet tracer as the background image.

\section{Implementation}

After all the smart devices being connected as shown in the figure 6 where the following devices are connected:-

- Fan

- Smart window

- Smart door

- Motion detector

- Furnace

- $\mathrm{Ac}$

- Temperature monitor

- Water level monitor

- Lawn Sprinkler

- Webcam

- Light

- Smoke Detector

- Siren

- Fire Sprinkler

- Garage Door 
International Journal of Intelligent Communication, Computing and Networks Open Access Journal (ISSN: 2582-7707)

https://doi.org/10.51735/ijiccn/001/26

In order to automate devices, sensors and web cam are placed [6]. Next step is to provide conditions for the devices to respond accordingly with the sensors. This can be done by tapping on the "Conditions" section where one can add, edit or remove the conditions for the functioning of the smart devices[7].

An example of motion detector condition for opening of door is given in the figure 7.

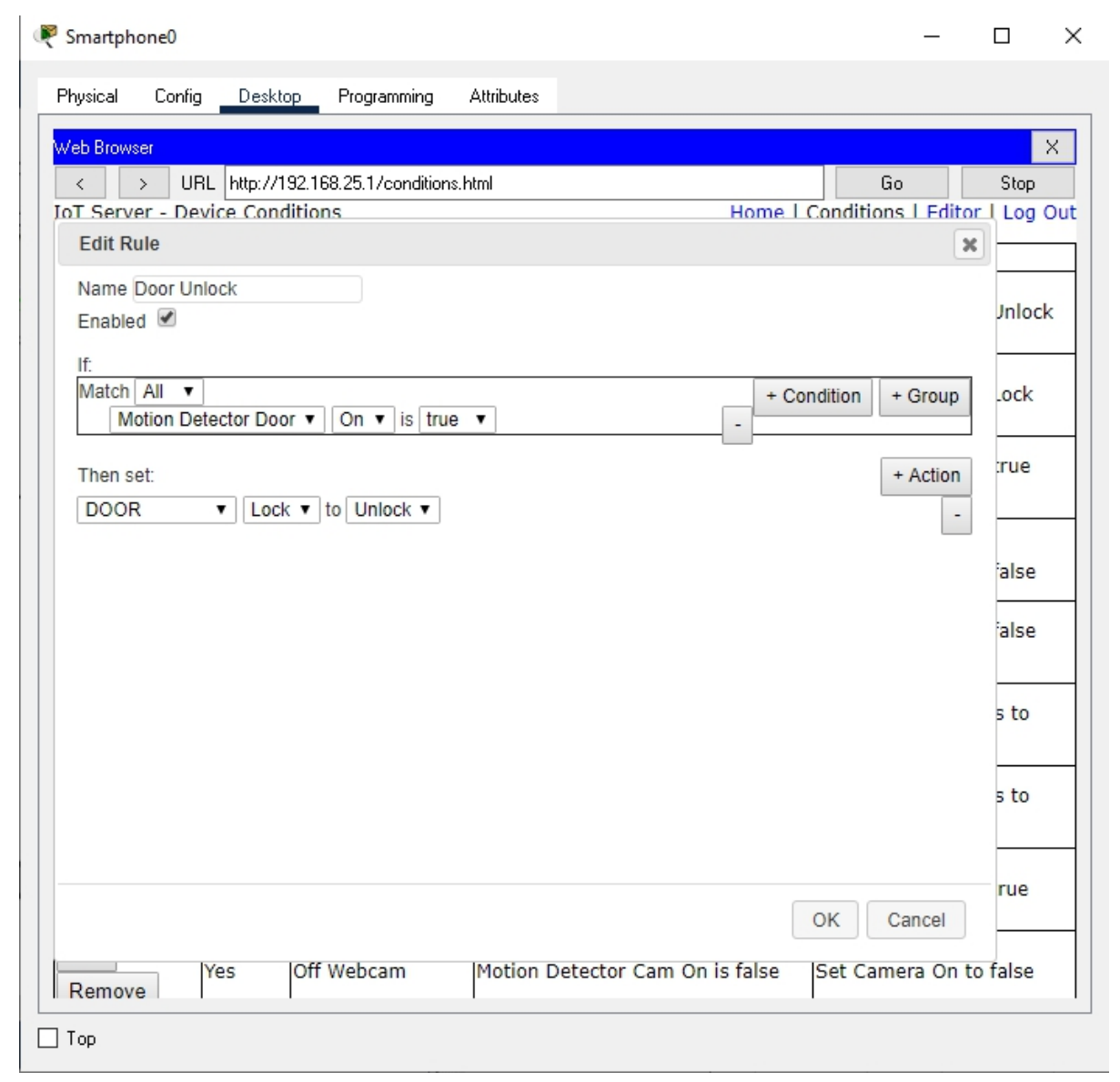

Figure 7: Condition for motion detector

So the implementation of designing Smart Home is done successfully by following all the necessary steps as stated above.

\section{Result}

Finally the designing of Smart Home is done showing the successful functioning of the sensors and smart devices which appears after following the procedure mentioned above. Figure 8 given below shows the functioning of Smart devices controlled by smartphone. 
International Journal of Intelligent Communication, Computing and Networks Open Access Journal (ISSN: 2582-7707)

https://doi.org/10.51735/ijiccn/001/26

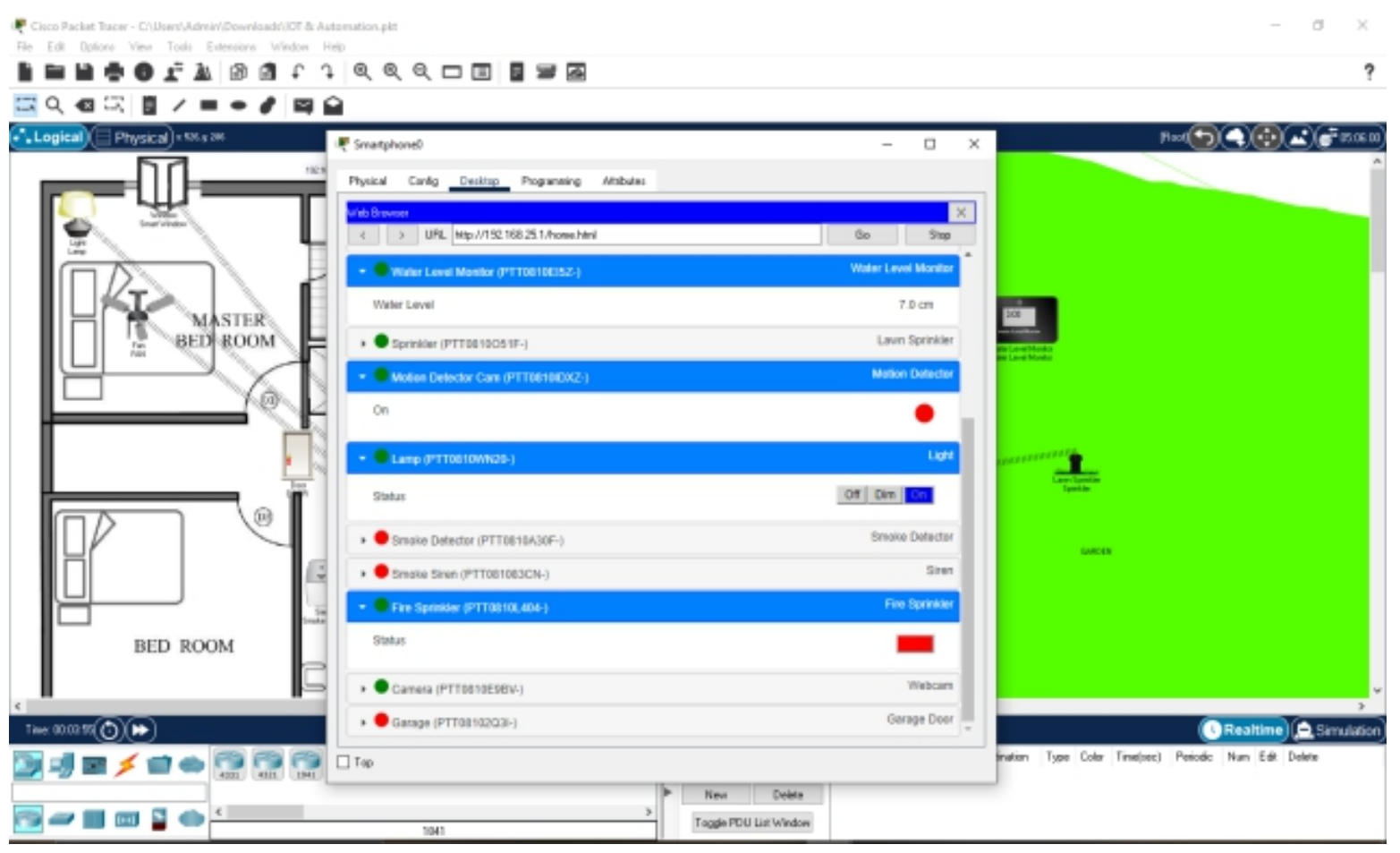

Figure 8: Functioning of Smart devices using CISCO packet racer

\section{Conclusion}

The main aim of the paper was to examine the idea of designing Smart Home using the IoT devices in the latest Cisco Packet Tracer (8.0) version and has given successful results. This paper do provides the layout of designing a Smart Home practically which leads to automation where both energy and time can be efficiently used. Such innovations and utilization of new technologies for accessing devices remotely improves the way of living. Such implementation empowers the growth in technologies to a great extent which increases the utilization of automation providing all the comforts of the technologies.

\section{References}

1. CiscoPacketTracerhttps://www.cisco.com/c/dam/en_us/training-events/netacad/course_catalog/docs/Cis co_PacketTracer_DS.pdf

2. International Journal of Scientific Research in Computer Science, E., \& IJSRCSEIT, I. T. (2020). Smart and secure home using IOT Simulations with Cisco Packet Tracer. International Journal of Scientific Research in Computer Science, Engineering and Information Technology. https://doi.org/10.32628/CSEIT206311.

3. International Journal of Engineering Research \& Technology https://www.researchgate.net/publication/338422167_Using_Cisco_Packet_Tracer_to_simulate_Smart_ Home.

4. Design and Implementation of Smart Home using WSN and IoT Technologies https://ieeexplore.iee.org/document/9311966.

5. Home automation https://en.wikipedia.org/wiki/Home_automation 
International Journal of Intelligent Communication, Computing and Networks

Open Access Journal (ISSN: 2582-7707)

https://doi.org/10.51735/ijiccn/001/26

6. Pitcheri Praveen kumar, Murali Krishna, M,RRamprakash. "Design and Implementation of Smart

Home using Cisco Packet Tracer Simulator 7.2

7. International Journal of Engineering Science Invention Research \& Development, "Implementing Smart Home Using Cisco Packet Tracer Simulator” Vol. IV, Issue VII, JANUARY 2018 